\title{
PENYELESAIAN SENGKETA PEMBAGIAN WARIS DAN PERTANAHAN DI DESA TRAYANG, KECAMATAN NGRONGGOT, KABUPATEN NGANJUK
}

\section{DISPUTE RESOLUTION FOR INHERITANCE AND LAND DISTRIBUTION IN TRAYANG VILLAGE, NGRONGGOT DISTRICT, NGANJUK REGENCY}

\author{
Hanum Rahmaniar Helmi, S.H., M.H \\ Fakultas Hukum Universitas Airlangga
}

\begin{abstract}
In the State of Indonesia, there are many cases of inheritance rights for widows and inheritance rights of adopted children that have been submitted to courts, both district and religious courts. This can have a significant impact related to the inheritance, especially in relation to the distribution received by each. State law regulates inheritance law, but it has not been able to accommodate the needs of the community, so that the problem is often resolved at court. Apart from that, the connection with serial marriages or polygamous marriages also often creates problems in society. Because it can lead to disputes between the family of the heir and the family left behind, based on the perspective of Islamic inheritance law and customary inheritance law, it can be explained more deeply about the rights that should be owned by widows and adopted children to minimize disputes that occur and achieve solutions to problems. win-win solution. Apart from inheritance law cases, there are also cases related to land disputes that often occur in society. For this reason, it is very important to hold community service against the background of the problems mentioned above. The service method is carried out by means of counseling and mentoring. The results obtained under the legal problems experienced by residents were varied, but most of them were in the field of inheritance and land. Therefore, the community service team agreed to provide counseling, guidance regarding inheritance and land laws in the village. At the time of counseling and mentoring, residents were very enthusiastic by asking various kinds of questions about inheritance and land law.
\end{abstract}

Keywords: dispute resolution, inheritance law, land law.

\begin{abstract}
Abstrak
Di Negara Indonesia terdapat banyak sekali kasus hak waris janda dan hak waris anak angkat yang diajukan pada pengadilan, baik itu pengadilan negeri maupun pengadilan agama. Hal ini dapat membawa dampak yang cukup signifikan terkait dengan pewarisan tersebut, terutama terkait dengan pembagian yang diterima masing-masing. Hukum negara telah mengatur hukum waris, namun belum dapat mengakomodir kebutuhan masyarakat, sehingga sering kali masalah tersebut diselesaikan di meja hijau. Di samping itu terkait dengan perkawinan serial atau perkawinan poligami juga acapkali menimbulkan masalah di masyarakat. Oleh karena dapat menimbulkan sengketa antar keluarga pewaris dengan keluarga yang ditinggalkan, berdasarkan perspektif hukum waris Islam dan hukum waris adat akan dapat dipaparkan lebih mendalam mengenai hak-hak yang seharusnya dimiliki oleh janda dan anak angkat agar dapat meminimalisir persengketaan yang terjadi dan dicapai pemecahan masalah yang win-win solution. Selain kasus hukum waris, juga terdapat kasus yang terkait dengan sengketa pertanahan yang sering terjadi di masyarakat. Untuk itu sangat penting diadakan pengabdian kepada masyarakat dengan latar belakang permasalahan-permasalahan tersebut di atas. Metode pengabdian yang dilakukan dengan cara penyuluhan dan pendampingan. Hasil yang diperoleh bawah Permasalahan hukum yang dialami oleh warga sangat beraneka-ragam, akan tetapi yang paling banyak ada di bidang waris dan juga pertanahan. Oleh karenanya, tim pengabdian masyarakat sepakat untuk melakukan penyuluhan, pembimbingan mengenai hukum waris dan
\end{abstract}


pertanahan di desa tersebut. Pada saat penyuluhan dan pembimbingan warga sangat antusias dengan mengajukan berbagai macam pertanyaan tentang hukum waris dan pertanahan

Kata Kunci: hukum pertanahan, hukum waris, penyelesaian sengketa

\section{PENDAHULUAN}

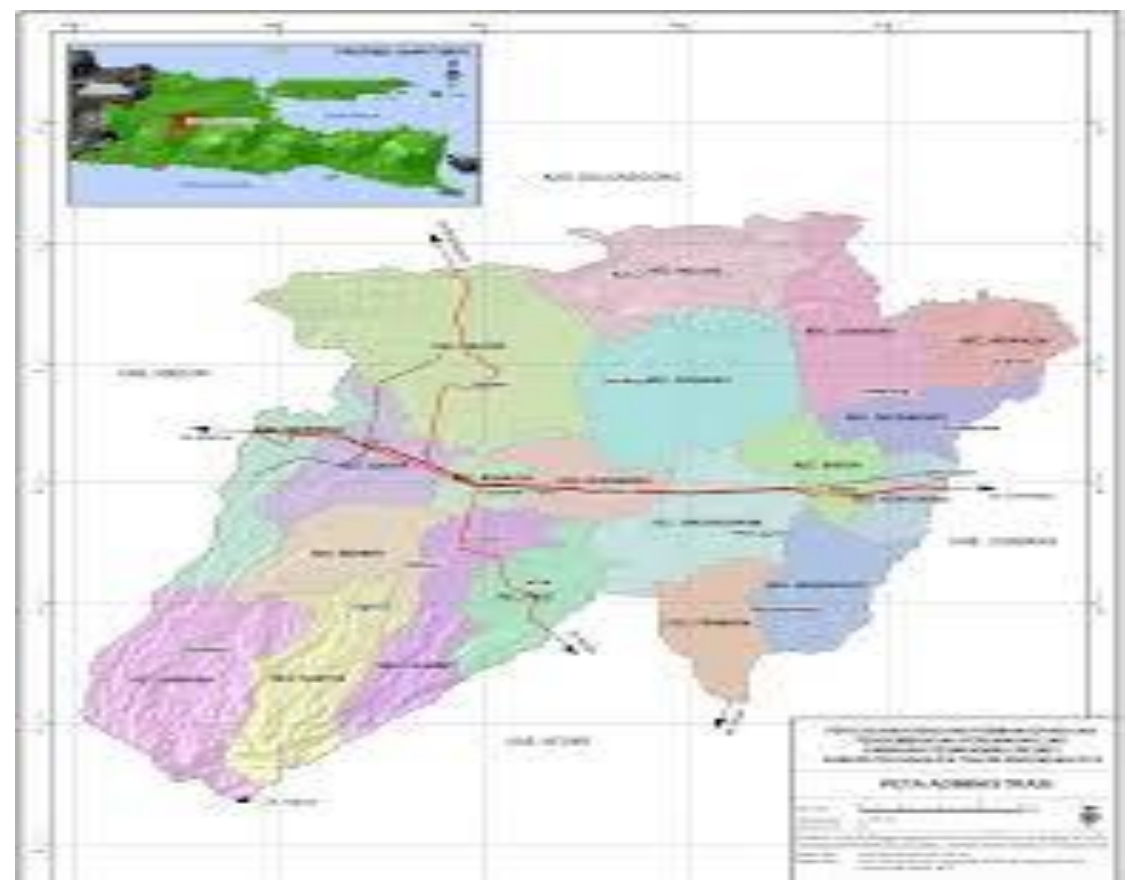

Gambar 1. Peta Kabupaten Nganjuk

Kabupaten Nganjuk terletak antara $111^{\circ} 5^{\prime}$ sampai dengan $112^{\circ} 13^{\prime}$ BT dan $7^{\circ} 20^{\prime}$ sampai dengan $7^{\circ} 59^{\prime}$ LS. Luas Kabupaten Nganjuk adalah sekitar $122.433 \mathrm{~km}^{2}$ atau setara dengan 122.433 Ha yang terdiri dari atas: Tanah sawah 43.052 Ha, Tanah kering 32.373 Ha, Tanah hutan $47.007 \mathrm{Ha}$

Dengan wilayah yang terletak di dataran rendah dan pegunungan, Kabupaten Nganjuk memiliki kondisi dan struktur tanah yang cukup produktif untuk berbagai jenis tanaman, baik tanaman pangan maupun tanaman perkebunan sehingga sangat menunjang pertumbuhan ekonomi dibidang pertanian. Kondisi dan struktur tanah yang produktif ini sekaligus ditunjang adanya sungai Widas yang mengalir sepanjang 69,332 Km dan mengairi daerah seluas 3.236 Ha, dan sungai Brantas yang mampu mengairi sawah seluas $12.705 \mathrm{Ha}$.

Jumlah curah hujan per bulan selama 2020 terbesar terjadi pada bulan Januari yaitu $7.416 \mathrm{~mm}$ dengan rata-rata $436 \mathrm{~mm}$. Sedangkan terkecil terjadi pada bulan November dengan jumlah curah hujan $600 \mathrm{~mm}$ dengan rata-rata $50 \mathrm{~mm}$. Pada bulan Juni sampai dengan bulan Oktober tidak terjadi hujan sama sekali.

Menurut Kementerian Pertanian (Kementan), Kabupaten Nganjuk menjadi salah satu daerah fokus pemerintah untuk menyerap bawang merah dan menjadi stok pemerintah tiap tahunnya. Daerah-daerah di Indonesia yang menjadi fokus penyerapan bawang merah adalah, Nganjuk, Brebes, Bima dan Solok. Sebagai sentra penghasil bawang merah di Jawa Timur dan salah satu fokus penyerapan bawang merah oleh 
pemerintah, bukan hal yang mengherankan bagi warga Kabupaten Nganjuk bila di mana-mana terlihat banyak orang menanam, memanen, menjemur, atau memperjualbelikan bawang merah. Namun, bagi pendatang atau mereka yang baru mengetahui fakta ini, menganggap Nganjuk ibarat sekumpulan surga bawang merah, tidaklah keliru.

Bila mengunjungi Nganjuk atau bermaksud membeli bawang merah langsung ke pusatnya, pasar Sukomoro dapat dipilih sebagai surga bawang merah. Pasar yang terletak di Jalan Surabaya-Madiun, Kecamatan Sukomoro ini dikenal sebagai pasar yang mengkhususkan diri pada transaksi jual-beli bawang merah. Di setiap sudut pasar ini hanya akan ditemui penjual dan pembeli bawang merah. Beberapa kecamatan yang menjadi penyuplai stok bawang merah di sentra bawang merah Sukomoro adalah Kecamatan Rejoso dan Kecamatan Bagor.

Masyarakat Jawa memiliki adat istiadat dan hukum adat yang merupakan warisan dari nenek moyang dan berlaku turun temurun dari generasi ke generasi. Salah satu hukum adat yang berlaku pada masyarakat di Kabupaten Nganjuk, yaitu Hukum Waris. Hukum waris yang berlaku pada masyarakat tersebut, adalah ada yang memberlakukan hukum waris Islam dan sebagian masyarakatnya memberlakukan hukum waris adat. Oleh sebab itu pada masyarakat tersebut banyak yang mengalami sengketa di bidang pewarisan. Di samping itu juga banyak kasus-kasus di bidang pertanahan yang terkait dengan pewarisan. Sehubungan dengan hal itu perlu kami melakukan pengabdian kepada masyarakat terkait dengan hukum waris dan hukum pertanahan pada masyarakat Kabupaten Nganjuk. Masyarakat Kabupaten Nganjuk pada umumnya, Kecamatan Ngronggot pada khususnya sangatlah perlu pengetahuan mengenai hukum waris dan pertanahan. Mengingat bahwa sebagian besar masyarakat di daerah tersebut adalah petani, sehingga akses pengetahuan tentang hukum waris dan pertanahan sangat minim. Selama ini penyelesaian sengketa hukum waris dan pertanahan masih jauh dari kata ideal, yaitu berdasarkan tata aturan hukum yang berlaku di Negara kita. Mereka biasanya hanya melibatkan orang-orang penting di desa. Sehingga penyelesaian sengketa tersebut tidak optimal dan acap kali menimbulkan permasalahan di kemudian hari.

Persoalan hukum waris akan menyangkut tiga unsur yaitu adanya harta warisan, pewaris dan adanya ahli waris. Dalam menyelesaikan sengketa harta warisan pada umumnya masyarakat menghendaki adanya penyelesaian yang rukun dan damai tidak terbatas pada para pihak yang berselisih tetapi juga termasuk semua anggota keluarga almarhum pewaris. Masalah tersebut antara lain seperti masalah anak luar kawin, anak angkat, perkawinan serial/perkawinan poligami dan masalah lain yang berkembang di masyarakat. Masyarakat bukan menghendaki adanya putusan menang kalah, sehingga menjadikan kekeluargaan menjadi renggang dan putus. Membawa masalah sengketa waris ke hadapan pengadilan sesungguhnya bukan untuk mencari penyelesaian damai atau adil sesuai dengan kesadaran hukum masyarakat tetapi mencari jalan keadilan menurut perundang-undangan, yurisprudensi dan perasaan hakim. Di samping itu, terdapat masalah terkait pendaftaran tanah hasil dari kewarisan yang acap kali terjadi di masyarakat, sehingga diperlukan adanya arahan agar tidak terjadi sengketa terkait pewarisan ini.

Sehubungan dengan penjelasan di atas, dosen sebagai bagian dari civitas akademika berkewajiban untuk menegakkan Tri Dharma Perguruan Tinggi, salah satunya adalah pengabdian masyarakat. Mengingat masyarakat Kabupaten Nganjuk, 
Provinsi Jawa Timur mayoritas menggunakan sistem hukum waris Adat dan hukum waris Islam dalam penyelesaian sengketa waris, maka Departemen Dasar Ilmu Hukum Fakultas Hukum Universitas Airlangga memilih Kabupaten Nganjuk Provinsi Jawa Timur sebagai tempat diselenggarakannya kegiatan pengabdian masyarakat pada kesempatan kali ini. Sehingga Judul Pengabdian Kepada Masyarakat yang digunakan adalah "Penyelesaian Sengketa Pembagian Waris dan Pertanahan di Desa Trayang, Kecamatan Ngronggot Kabupaten Nganjuk".

\section{METODE PENGABDIAN MASYARAKAT}

Metode pelaksanaan kegiatan Pengmas ini dapat digambarkan dengan bagan sebagai berikut:

\section{Bagan 1: Metode Pelaksanaan Pengmas}

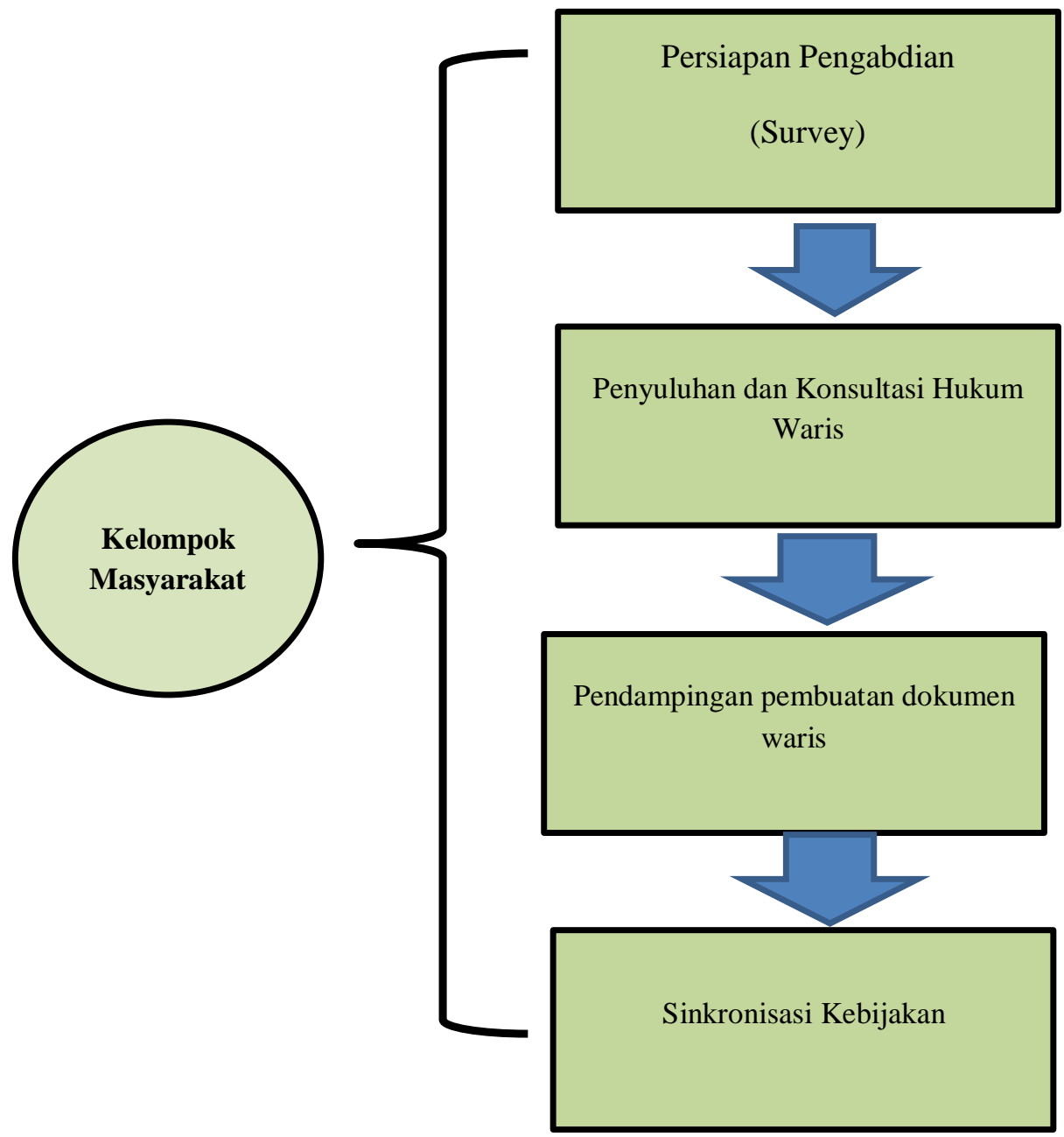

Bagan diatas menjelaskan proses rangkaian kegiatan Pengmas akan dimulai dari tahapan persiapan kemudian dilanjutkan dengan penyuluhan dan konsultasi hukum waris, lalu pendampingan pembuatan dokumen waris dan yang terakhir sinkronisasi kebijakan.

Tahap pelaksanaan dari kegiatan ini dilakukan pada April sampai dengan Oktober 2020. Rincian kegiatan ini adalah sebagai berikut:

Tahap Persiapan adalah survei lokasi sekaligus mengurus perijinan Kegiatan 
Pengabdian Kepada Masyarakat ke di Desa Trayang, Kecamatan Ngronggot, Kabupaten Nganjuk Provinsi Jawa Timur.

Tahap Penyuluhan adalah memberikan penyuluhan dan konsultasi hukum waris dengan mengundang Kepala Desa dan perangkat Desa di lingkungan Desa Trayang, Kecamatan Ngronggot, Kabupaten Nganjuk Provinsi Jawa Timur.

Tahap Pendampingan adalah melakukan pendampingan langsung terhadap kelompok tani dan ibu rumah tangga untuk membuat surat pembagian waris dan administrasi pertanahan.

Tahap sinkronisasi kebijakan adalah upaya sinkronisasi kebijakan antara Kepala Desa dan perangkat Desa Trayang, Kecamatan Ngronggot, Kabupaten Nganjuk Provinsi Jawa Timur yang berkaitan dengan hukum waris.

\section{HASIL DAN PEMBAHASAN}

Setelah dilakukan beberapa tahap kunjungan yang merupakan bagian dari kegiatan pengabdian kepada masyarakat ini, selanjutnya warga masyarakat membutuhkan advokasi hukum selain dalam bidang hukum waris dan pertanahan. Hal ini terlihat dari pertanyaan-pertanyaan yang dilontarkan warga tidak hanya seputar hukum waris dan pertanahan saja, namun lebih dari itu ada beberapa dari warga yang melakukan konsultasi hukum kepada kami. Namun dikarenakan kondisi saat ini dalam masa pandemi, maka selanjutnya konsultasi tentang hukum waris, pertanahan dan bidang lainnya dilakukan secara online.

Selain itu, untuk menunjukkan bahwa kegiatan yang sudah dilakukan oleh tim pengabdian kepada masyarakat membuahkan hasil, maka agenda selanjutnya yaitu terus melakukan pendampingan terhadap warga Desa Trayang, Kecamatan Ngronggot, Kabupaten Nganjuk yang belum mampu membuat surat pembagian waris dan pertanahan. Ada beberapa warga yang sudah bisa membuat surat pembagian waris dan administrasi pertanahan, namun ada juga yang pemahamannya belum maksimal. Oleh karenanya tim pengabdian kepada masyarakat terus mengawal warga Desa Trayang, Kecamatan Ngronggot, Kabupaten Nganjuk agar dalam pembuatan dokumen waris dan pertanahan tersebut.

Dengan adanya kegiatan ini maka pengetahuan dan pemahaman dalam bidang Hukum terutama Hukum Waris dan Pertanahan yang dimiliki oleh warga Desa Trayang, Kecamatan Ngronggot Kabupaten Nganjuk semakin meningkat seiring pula dengan meningkatnya kemampuan warga Desa untuk menganalisis tersendiri permasalahanpermasalahan hukum yang sedang mereka hadapi.

Selain itu juga meningkatnya kemampuan warga terkait penyelesaian sengketa yang berkaitan dengan waris dan pertanahan yang sering kali terjadi di dalam masyarakat sesuai dengan ketentuan peraturan perundang-undangan dan perkembangan yurisprudensi yang ada. Hal ini tampak ketika tim pelaksana melakukan kegiatan ketiga, para peserta sudah dapat memahami materi yang telah diberikan pada kegiatan kedua.

Selain itu dengan adanya pendampingan terhadap warga Desa Trayang, Kecamatan Ngronggot Kabupaten Nganjuk maka mereka menjadi terampil membuat administrasi waris serta yang terkait dengan pertanahan. Pemahaman mereka dalam aspek hukum ini semakin dilengkapi juga dengan pemahaman terkait prosedur dan tata cara pembagian waris berdasarkan hukum waris Islam dan hukum waris Islam serta pertanahan.

Setiap tahap pelaksanaan kegiatan di atas akan menjadi catatan penting tersendiri bagi tim pelaksana pengabdian masyarakat. Oleh karenanya, untuk mencapai sebuah keberhasilan atas pelaksanaan pengabdian masyarakat tersebut, tim pelaksana 
pengabdian masyarakat akan menuangkan dalam sebuah artikel ilmiah. Dengan harapan bahwa artikel ilmiah tersebut nantinya akan membawa manfaat bagi masyarakat secara luas khususnya yang membutuhkan pengetahuan tentang penyelesaian sengketa di bidang pembagian waris dan pertanahan. Selain artikel ilmiah, sebagai luaran pengabdian masyarakat, tim pengabdian masyarakat juga mengunggah hasil kegiatan pada media massa elektronik. Agar siapa pun yang membutuhkan informasi mengenai topik pengabdian masyarakat ini, dapat mengakses dengan mudah.

\section{SIMPULAN DAN SARAN}

Dari uraian yang telah diberikan pada bab sebelumnya, dapat disimpulkan bahwa Desa Trayang, Kecamatan Ngronggot Kabupaten Nganjuk- Jawa Timur merupakan desa yang memiliki permasalahan hukum yang kompleks. Hal ini terlihat pada saat tim pengabdian masyarakat melakukan survei di desa tersebut. Permasalahan hukum yang dialami oleh warga sangat beraneka-ragam, akan tetapi yang paling banyak ada di bidang waris dan juga pertanahan. Oleh karenanya, tim pengabdian masyarakat sepakat untuk melakukan penyuluhan, pembimbingan mengenai hukum waris dan pertanahan di desa tersebut. Pada saat penyuluhan dan pembimbingan warga sangat antusias dengan mengajukan berbagai macam pertanyaan tentang hukum waris dan pertanahan. Fokus kegiatan Pengabdian Kepada Masyarakat ini memang ada pada bidang hukum namun tim pelaksana juga memaksimalkan kegiatan ini dengan cara membantu mereka menyelesaikan masalah di luar bidang hukum. Hal ini bertujuan agar masyarakat bisa secara mandiri menyelesaikan masalah hukumnya, atau lebih tepatnya membuat masyarakat desa tersebut lebih melek hukum.

Dari uraian yang telah dilakukan pada bab sebelumnya, maka ada saran yang diajukan oleh tim pelaksana yaitu melihat antusiasme dan kebutuhan masyarakat akan pentingnya advokasi di bidang hukum khususnya hukum waris dan pertanahan ini, ke depannya perlu dilakukan penyuluhan hukum secara berkelanjutan. Penyuluhan hukum yang dilakukan seharusnya tidak hanya pada bidang hukum waris dan pertanahan namun juga bidang hukum yang lainnya, seperti hukum perdata, pidana dll. Karena sebagian besar masyarakat desa ini adalah para petani yang wawasan akan hukumnya sangat minim.

\section{DAFTAR PUSTAKA}

Hazairin, Hukum Kewarisan Bilateral Menurut Al-Quran dan Hadists, Tinta Mas, Jakarta, 1980.

Ismail, Nurhasan, Perkembangan Hukum Pertanahan Indonesia (Pendekatan Ekonomi Politik), Huma dan Magister Hukum Universitas Gadjah Mada, Yogyakarta, 2007.

M.Hadjon, Philipusdan Sri Djatmiati, Tatiek Argumentasi Hukum, Gadjah Mada University Press, Yogjakarta, 2005

Marzuki, Peter Mahmud, Pengantar Ilmu Hukum, Edisi Revisi, Prenadamedia Group, Jakarta, 2011.

Mertokusumo, Sudikno, Mengenal Hukum Suatu Pengantar, Liberty, Yogyakarta, 2008 . 
Hanum Rahmaniar Helmi : Penyelesaian Sengketa Pembagian Waris dan Pertanahan Di Desa Trayang, Kecamatan Ngronggot, Kabupaten Nganjuk

Nunk, 11 Prodi UA masuk Jajaran Prodi Terbaik di Indonesia, warta unair,http://warta.unair.ac.id/warta.1508.html, 14-06-2013.

Ter Haar, Asas-Asas Dan Susunan Hukum Adat, (terjemahan K.Ng. Soebakti Poesponoto), 1999. 